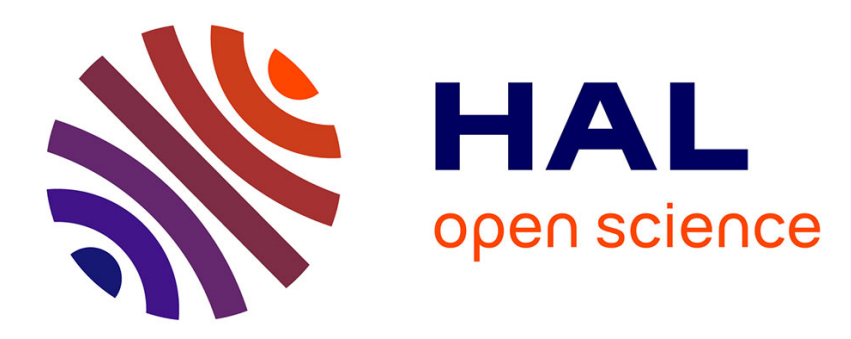

\title{
Smart Grid Voltage Sag Detection using Instantaneous Features Extraction
}

\author{
Yassine Amirat, Mohamed Benbouzid, Wang Tianzhen, Sylvie Turri
}

\section{To cite this version:}

Yassine Amirat, Mohamed Benbouzid, Wang Tianzhen, Sylvie Turri. Smart Grid Voltage Sag Detection using Instantaneous Features Extraction. IEEE IECON 2013, Nov 2013, Vienne, Austria. pp.7394-7399. hal-00926235

\section{HAL Id: hal-00926235 https://hal.science/hal-00926235}

Submitted on 9 Jan 2014

HAL is a multi-disciplinary open access archive for the deposit and dissemination of scientific research documents, whether they are published or not. The documents may come from teaching and research institutions in France or abroad, or from public or private research centers.
L'archive ouverte pluridisciplinaire HAL, est destinée au dépôt et à la diffusion de documents scientifiques de niveau recherche, publiés ou non, émanant des établissements d'enseignement et de recherche français ou étrangers, des laboratoires publics ou privés. 


\title{
Smart Grid Voltage Sag Detection using Instantaneous Features Extraction
}

\author{
Yassine Amirat, Mohamed Benbouzid, Tianzhen Wang and Sylvie Turri
}

\begin{abstract}
Smart grids have initiated a radical reappraisal of distribution networks function where the integration of renewable energy sources, load demand control, and effective use of the network are indexed as the most important keys for smart grid expansion and deployment regardless each country policies. One of the most efficient ways of effective use of these grids would be to continuously monitor their conditions. This allows for early detection of power quality degeneration facilitating therefore a proactive response, prevent a fault ride-through the renewable power sources, minimizing downtime, and maximizing productivity.

In this smart grid context, this paper proposes the evaluation and comparison of advanced signal processing tools, namely the Hilbert transform and the ensemble empirical mode decomposition method for the detection of voltage sags as they are the most commonly encountered power quality disturbances.
\end{abstract}

Index Terms-Smart grid, voltage sag detection, power quality (PQ), Hilbert Transform (HT), ensemble empirical mode decomposition (EEMD).

\section{INTRODUCTION}

Renewable energy conversion systems are the fastestgrowing sources of new electric generation in the world and it is expected to remain so for sometimes. These systems offer an alternative and emerging solution by deploying hybrid power plant offshore or onshore, where there are substantial renewable resources, leading to a best electricity generating opportunities. With the deployment of distributed renewable power generation; the electricity networks are undergoing wholesale changes both from generation and users sides because the power flow is becoming bidirectional and the users are playing an active role in managing their demand for electricity [1]. Despite accumulated experienced in the conventional electric distribution networks, the task of distributed networks is still an art. It has become more challenging as far as the generation system is moved nearby the distribution level and this is achieved by using a set of micro grids and energy islands based on renewable sources, connected to the main grid as illustrated in Fig. 1 [2-3].

Y. Amirat is with ISEN, EA 4325 LBMS, 20, Rue Cuirassé Bretagne, 29200 Brest, France (e-mail: Yassine.Amirat@isen.fr).

M.E.H Benbouzid and S. Turri are with the University of Brest, EA 4325 LBMS, Rue de Kergoat, CS 93837, 29238 Brest, France (e-mail: Mohamed.Benbouzid@univ-brest.fr, Sylvie.Turri@univ-brest.fr).

T. Wang is with the Shanghai Maritime University, Department of Electrical Automation, 201306 Shanghai, China (email: tzwang@shmtu.edu.cn).
The philosophy of smart grids is giving the distribution network more flexibility by rending it able to meet the power demand needs and have islanding fast capabilities when a fault occurs such as voltage sags or power outage. So, key considerations when deploying smart grids are their availability, reliability, and profitability; in order to fulfill power demand according to PQ standards. In this context, voltage sags automated detection is indexed as an essential requirement for a condition monitoring system in order to meet PQ standards [4-5]. Since smart grids are a collection of diverse set of power generation sources, including large power plants and distributed generation sources, energy storage systems, it is then difficult to deal with such a complex system through conventional procedures used in classical distribution networks particularly during faults and system emergencies.

It is therefore obvious that real-time monitoring and remote control is a key issue that needs to be addressed to make a grid more intelligent and self-healing. This requires much more sophisticated computer-oriented monitoring than in a classical grid [2]. In this context, signal processing is certain to play a significant role in dealing with the complexity and uncertainty associated with a smart grid [6].

For voltage sag detection, there is a wide range of technology and methods derived from contemporary power systems [7-10]. These methods are based on electrical quantity signatures analysis (current, voltage, power, etc.). Indeed, those quantities are easily accessible or evaluated during operation. Electrical quantities analysis usually involves the use of reference frame transformations such as Park's vector [11] or three-phase system symmetrical components or space vector [5], and other techniques based upon them. These techniques however assume that voltage and current quantities are pure sine waves, while in real-world the electrical quantities are polluted by harmonics produced by power electronic devices in both sides of the smart grid, and transient spikes due to grid apparatus maneuvers. It is therefore obvious the Fast Fourier Transform (FFT), and other techniques based upon it, are no longer valid even they has been used in some cases [7]. Advanced signal processing techniques are therefore required to deal with the complexity and uncertainty associated with a smart grid. In [12], a Teager-Kaiser energy operator has been proposed for power system oscillations detection and analysis. However, this operator is highly affected by noises. In [13], wavelets and Prony method were used. Wavelets however require properly windowed disturbing events, to ensure accurate computations. Moreover, Prony method highly depends on the system parameters and operating modes. 


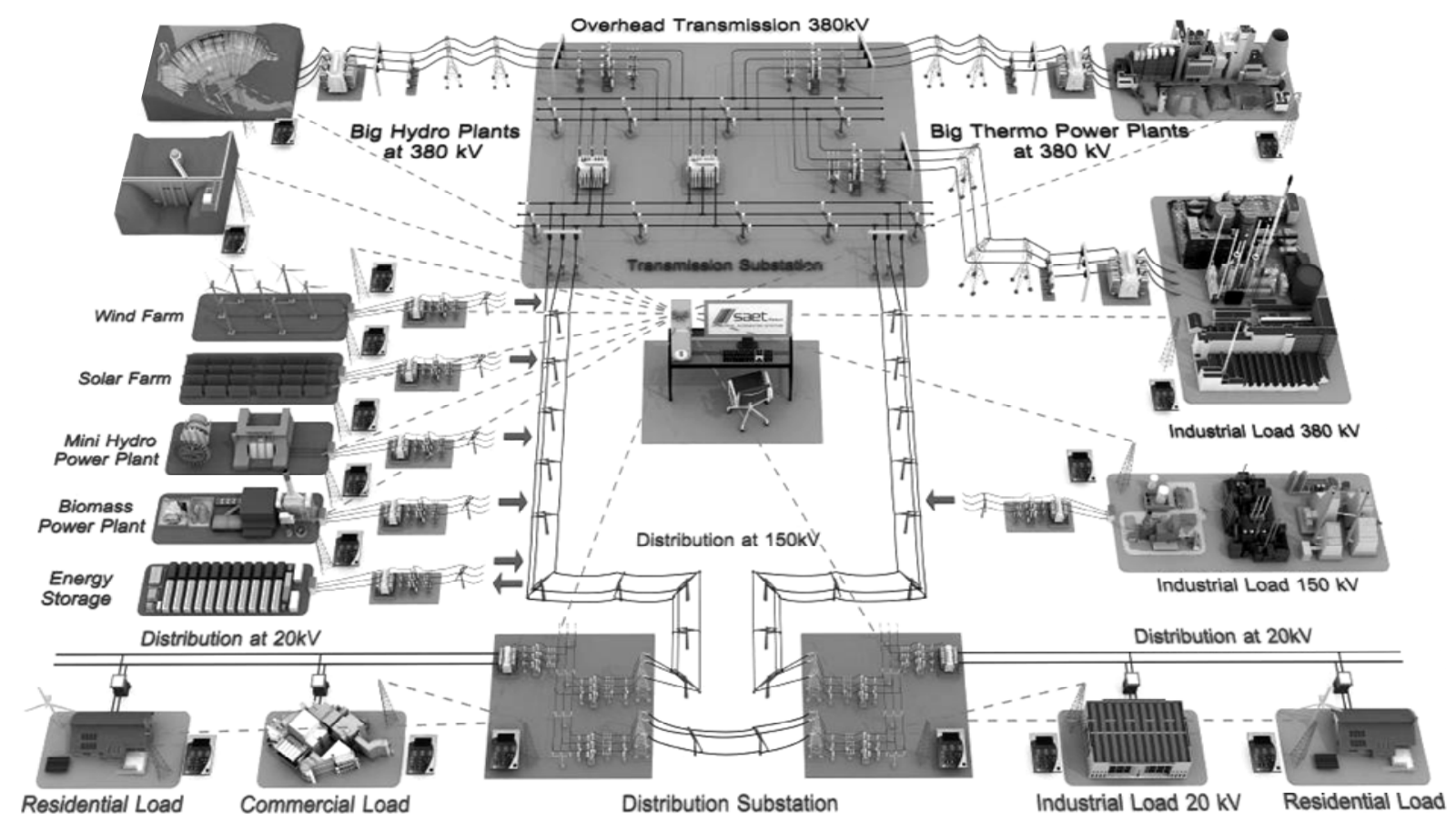

Fig. 1. A smart grid topology [C SAET].

As voltage sags lead to transient phenomena (voltage unbalance and voltage/current waveform disturbances) [14], it seems that the focus should be on transient signal processing techniques. In this disturbing and transient context, it is therefore proposed to assess and to compare two advanced non stationary signal processing techniques: Hilbert transform and the ensemble empirical mode decomposition method. In particular, distinct features will be extracted from the instantaneous power for voltage sags detection and characterization [15-16].

\section{Voltage SAGS CHARACTERIZATION}

Voltage sags are indexed as the most important power quality issue. They are a transient deviation of the RMS supply voltage from a reference value with typical dip depths ranging from 0.9 to $0.5 \mathrm{pu}$ of a 1 pu nominal [7]; lasting from few milliseconds to few cycles; caused by abrupt increases in loads such as phase to phase or phase to ground short circuits, they are also caused by abrupt increases in source impedance, typically caused by a loose connection [14].

The most usual voltage sags signatures are depicted in Fig. 2 [5]. During a voltage sag three-phase system balanced conditions are no longer valid leading to possible disastrous consequences on the user end-loads and on the smart grid itself.

Voltage sag characterization concerns events quantification through a limited number of parameters. These parameters depend on the field of study. However, main characterization methods use two parameters to determine the severity of a voltage sag: magnitude (or "remaining voltage") and duration [3]. In the context of a smart grid, it is therefore important to know whether voltage sag exists and afterward estimate its duration.
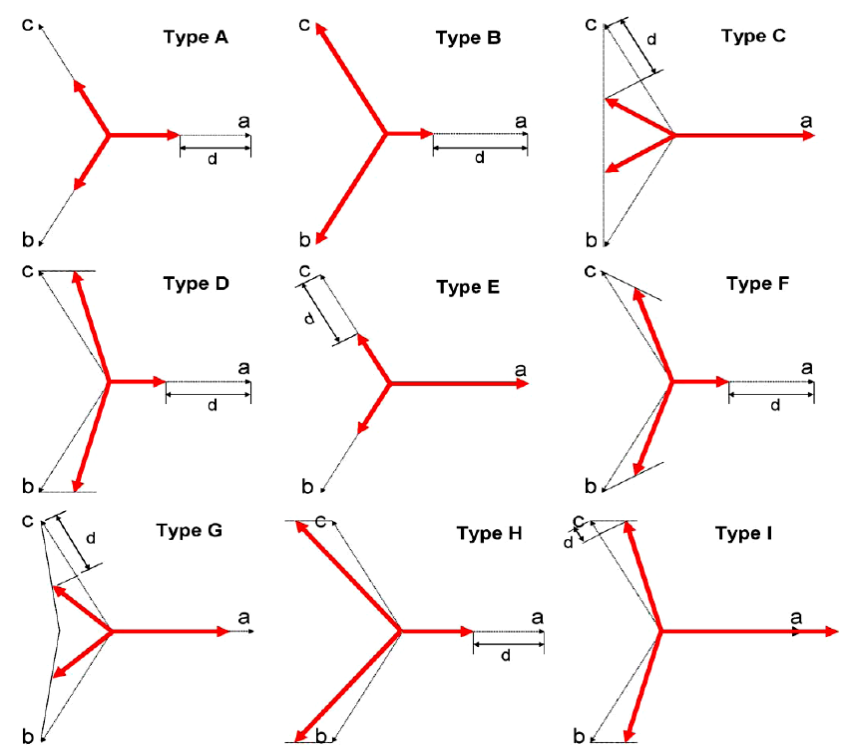

Fig. 2. Voltage sag main signatures [5].

\section{Voltage SAgs Detection TeChNIQUES}

To assess the ability of the compared fault detection techniques, real data were used. Those data were fed by the DOE/EPRI National Database Repository of Power System Events [17].

Figure 3 depicts the acquired voltage and currents when a fault occurs on a transmission line during a thunderstorm causing SARFI-70 sag [18].

Since voltage sags effect arises in voltages and currents, it seems more relevant to use the three-phase instantaneous power given by 

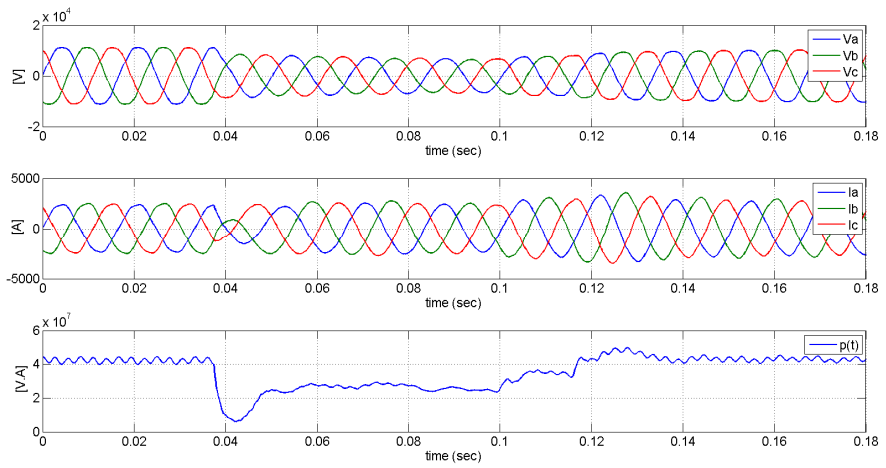

Fig. 3. Phase voltages, currents, and the total instantaneous power before, during and after voltage sag.

$p(t)=\sum_{k=a, b, c} v_{k}(t) i_{k}(t)$

The instantaneous power depicted in Fig. 3 clearly show that, for voltage sags detection (occurrence time), it is more convenient to track the power Instantaneous Amplitude (IA). Estimating IA will therefore allow extracting statistical features for the fault characterization. In this context, there exist many IA estimation techniques in the literature and the most popular include Hilbert Transform (HT) [19-20]. Furthermore for non stationary signals the Empirical Mode Decomposition (EMD) can be investigated as it is considered as one of the emerging methods for transient signal processing [21-22].

Figure 4 is given to illustrate the adopted approach for feature extraction and therefore comparison of the two chosen techniques.

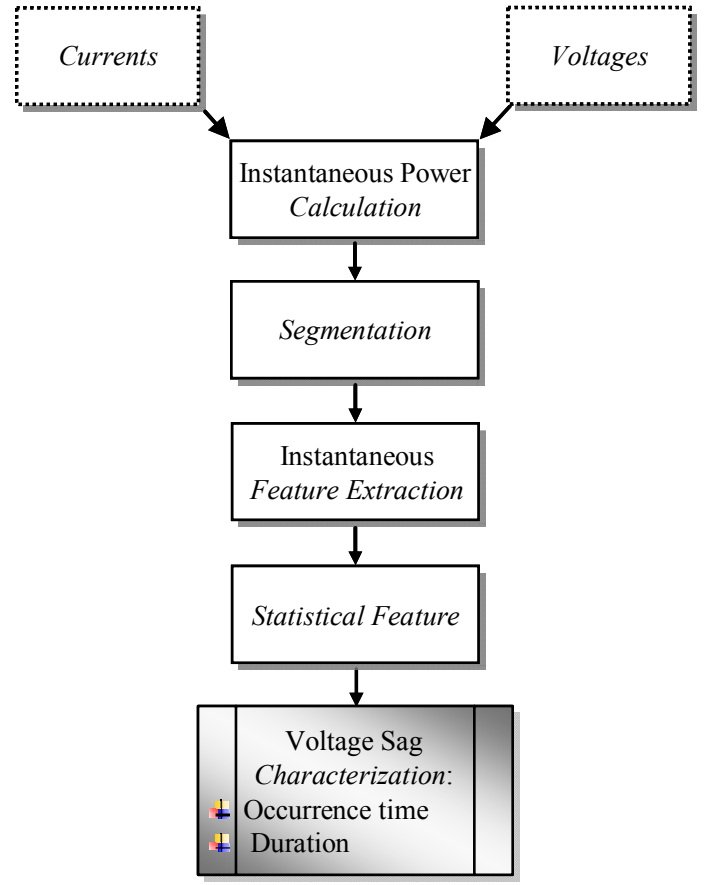

Fig. 4. Adopted approach for feature extraction.

\section{A. Hilbert Transform}

Hilbert transform is used to estimate the instantaneous amplitude since it is usually more robust against noise than the Teager energy operator. The instantaneous power $p(t)$ Discrete Hilbert Transform (DHT) is given by

$$
H[p(n)]=F^{-1}\{F\{p(n)\} u(n)\}
$$

where $F\{$.$\} and F^{-1}\{$.$\} correspond to the FFT and Inverse FFT,$ respectively, and $u(n)$ is defined as

$$
u(n)= \begin{cases}1, & n=0, \frac{N}{2} \\ 2, & n=1,2, \ldots ., \frac{N}{2}-1 \\ 0, & n=\frac{N}{2}+1, \ldots, N-1\end{cases}
$$

and $N$ is the data sample number.

Using (1), the instantaneous amplitude $\hat{p}(n)$ is given by

$$
\hat{p}(n)=\sqrt{p^{2}(n)+(H[p(n)])^{2}}
$$

Figure 5 show therefore the instantaneous power and its instantaneous amplitude.

The shortest path to the IA information is the statistic variance $\sigma^{2}$ given by

$$
\sigma_{\hat{p}}^{2}=\frac{1}{N} \sum_{n=0}^{N-1}\left[\hat{p}(n)-\mu_{\hat{p}}\right]^{2}
$$

For voltage sags characterization, HT is carried-out during equal segments as depicted in Fig. 6. The achieved IAs for each segment are illustrated by Fig. 7 (for 70 samples of the instantaneous power). Since the $1^{\text {st }}$ segment is fault-free, all the other segments are therefore compared to it by computing the IA static variance ratio of each segment (i.e. 2, 3, ., 20) over the reference one. The achieved results are summarized in Table 1.
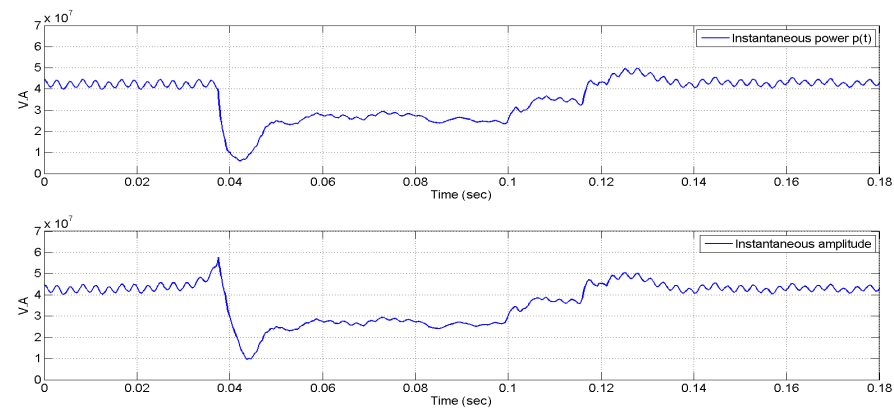

Fig. 5. Instantaneous power and its amplitude before, during and after voltage sag. 


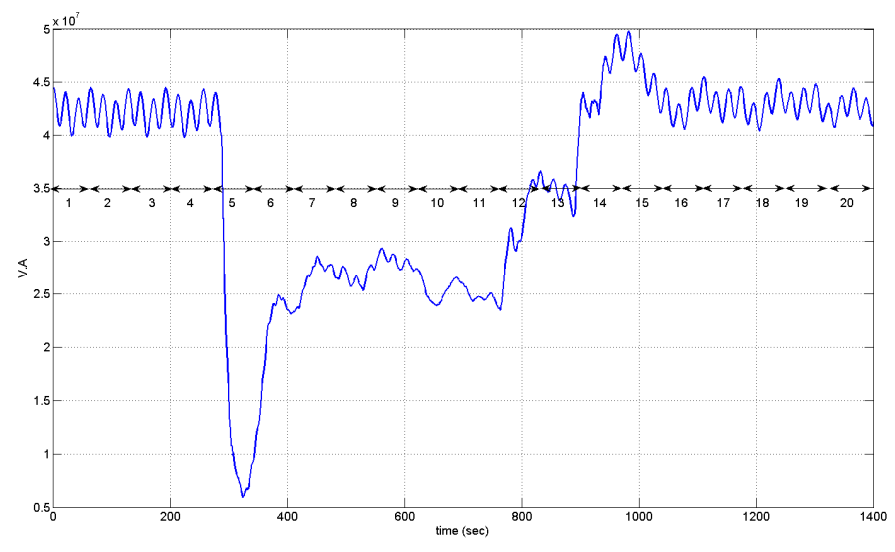

Fig. 6. Instantaneous power segmentation.

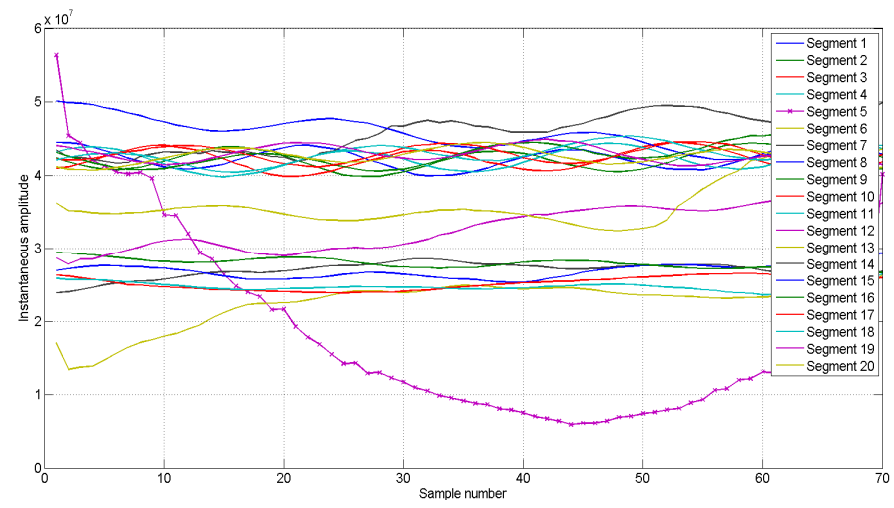

Fig. 7. Instantaneous power IA in each segment.

Table 1. IA statistics for each segment.

\begin{tabular}{|c|c|c|c|c|c|}
\hline Segment & 1 & 2 & 3 & 4 & 5 \\
\hline$\frac{\sigma_{i^{t h} \text { segment }}^{2}}{\sigma_{1^{t} \text { segment }}^{2}}$ & 1.000 & 0.903 & 0.925 & 0.978 & 85.223 \\
\hline Segment & 6 & 7 & 8 & 9 & 10 \\
\hline$\frac{\sigma_{i^{\prime \prime} \text { segment }}^{2}}{\sigma_{1^{t} \text { segment }}^{2}}$ & 5.210 & 0.604 & 0.538 & 0.241 & 0.451 \\
\hline Segment & 11 & 12 & 13 & 14 & 15 \\
\hline$\frac{\sigma_{i^{\prime \prime} \text { segment }}^{2}}{\sigma_{1^{s} \text { segment }}^{2}}$ & 0.186 & 4.418 & 6.636 & 3.522 & 2.285 \\
\hline Segment & 16 & 17 & 18 & 19 & 20 \\
\hline$\frac{\sigma_{i^{\prime \prime} \text { segment }}^{2}}{\sigma_{I^{t} \text { segment }}^{2}}$ & 1.071 & 0.664 & 0.809 & 0.5821 & 0.604 \\
\hline
\end{tabular}

\section{B. Ensemble Empirical Modal Decomposition}

The EMD is an adaptive time-frequency data analysis method for nonlinear and non-stationary signals, and has focused considerable attention and has been indexed recently for power system fault detection and analysis [12], [15]. Indeed and contrary to well-known decomposition techniques, EMD is intuitive and direct, with the basic functions based on and derived from the data. It is used to decompose the multicomponent signal into a series of IMFs based on the signal time-scale local characteristics. However, one major drawback of the EMD is the mode mixing. This phenomenon means that the detail related to one scale can appear in two different intrinsic modes. To overcome this drawback, the EEMD was introduced [21-22]. The EEMD is described as a new noiseadded method, which mitigate automatically the EMD modemixing. It is described in the flowchart given in Fig. 8.

After decomposing the instantaneous power according to the EEMD algorithm, several IMFs were obtained. The most energized is the $4^{\text {th }}$ one. Figure 9 depicts then the instantaneous power and its $4^{\text {th }}$ IMF. In particular, it is clearly shown that this IMF is very sensitive to the voltage sag occurrence and its duration. This is confirmed when intrinsic modes decomposition is carried-out during the same abovedescribed 20 segments (for the 70 samples of the instantaneous power).

After the EEMD processing, the same statistical criterion is computed for the $4^{\text {th }}$ IMF for each segment. The achieved results are summarized in Table 2.

In order to have more readable information for comparison purposes, Tables 1 and 2 are results are summarized in Fig. 11. According to the electrical quantities waveforms (Fig. 3), from the $2^{\text {nd }}$ to the $4^{\text {th }}$ segment, normal operation is confirmed by the variance reduced value, for both techniques. At a voltage sag occurrence $\left(5^{\text {th }}\right.$ segment), the criterion increases to 85 times for HT and to 132 times for EEMD; this means that both HT and EEMD are able to detect voltage sag occurrence. It should be noted that the EEMD seems slightly more sensitive the fault occurrence. Moreover, and for estimation of the voltage sag duration, it seems obvious that EEMD remains sensitive to the voltage sag (from segments 6 to 18).

From this brief comparative analysis, it seems that EEMD, using the instantaneous power $4^{\text {th }} \mathrm{IMF}$, could be considered as a reliable technique for voltage sag detection and characterization (occurrence and duration), using instantaneous power segmentation and a reduced set of sample.

\section{CONCLUSION}

This paper dealt a comparative analysis of advanced signal processing tools, namely the Hilbert transform and the ensemble empirical mode decomposition method, for the detection of voltage sags, in this smart grid context. It has been proposed a specific features extraction approach using the instantaneous power as the prime variable. Indeed, it has been first sample in regular segment.

Instantaneous features are afterwards extracted through the Hilbert transform and the EEMD. 


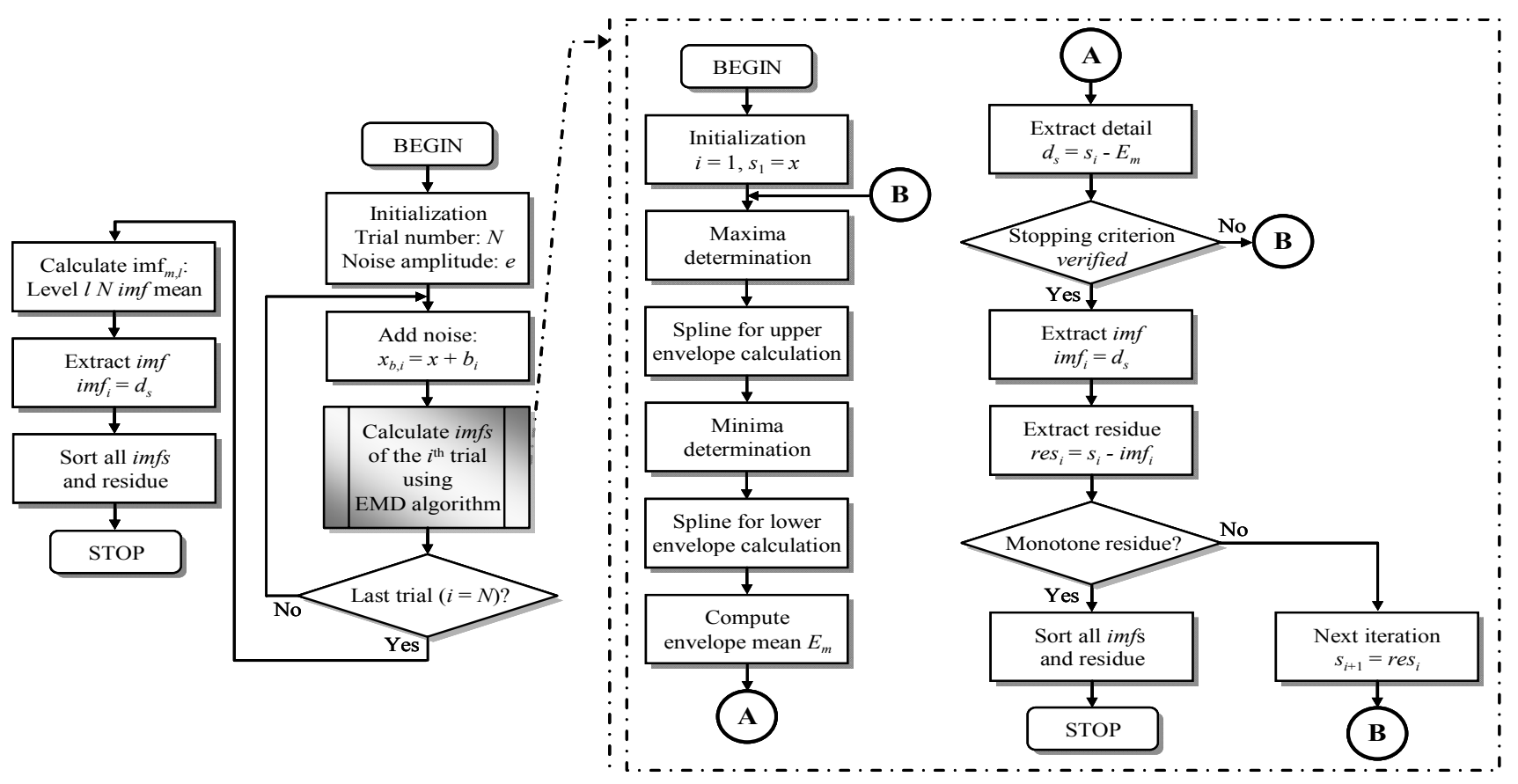

Fig. 8. EEMD algorithm flowchart.
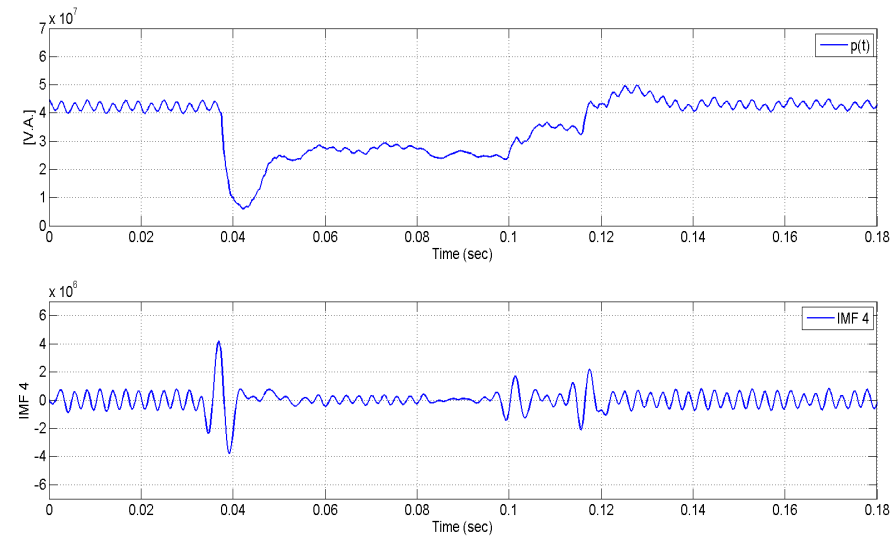

Fig. 9. Instantaneous power and its $4^{\text {th }} \mathrm{IMF}$ before, during and after voltage sag.

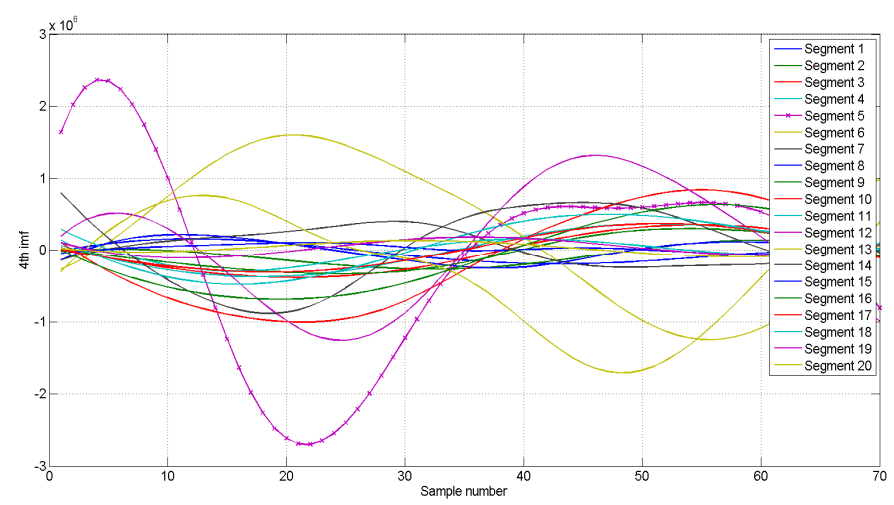

Fig. 10. Instantaneous power $4^{\text {th }}$ IMF for each processing segment.
Table 2. $4^{\text {th }}$ IMF statistics for each segment.

\begin{tabular}{|c|c|c|c|c|c|}
\hline Segment & 1 & 2 & 3 & 4 & 5 \\
\hline$\frac{\sigma_{i^{\text {th }} \text { segment }}^{2}}{\sigma_{1^{\text {st }} \text { segment }}^{2}}$ & 1.0000 & 1.2687 & 5.0897 & 5.0476 & 132.446 \\
\hline Segment & 6 & 7 & 8 & 9 & 10 \\
\hline$\frac{\sigma_{i^{\text {th }} \text { segment }}^{2}}{\sigma_{1^{\text {st }} \text { segment }}^{2}}$ & 64.6928 & 3.4446 & 1.5039 & 3.6355 & 31.211 \\
\hline Segment & 11 & 12 & 13 & 14 & 15 \\
\hline$\frac{\sigma_{i^{\text {th }} \text { segment }}^{2}}{\sigma_{1^{\text {st }} \text { segment }}^{2}}$ & 1.6115 & 46.4227 & 48.2043 & 19.0097 & 0.178 \\
\hline Segment & 16 & 17 & 18 & 19 & 20 \\
\hline$\frac{\sigma_{i^{\text {th }} \text { segment }}^{2}}{\sigma_{1^{\text {st }} \text { segment }}^{2}}$ & 16.4797 & 4.1726 & 8.2415 & 0.6626 & 0.392 \\
\hline
\end{tabular}

It was therefore found that EEMD, using the instantaneous power $4^{\text {th }}$ IMF, is more fault-sensitive and could be considered as a reliable technique for voltage sag detection and then smart grid monitoring. 

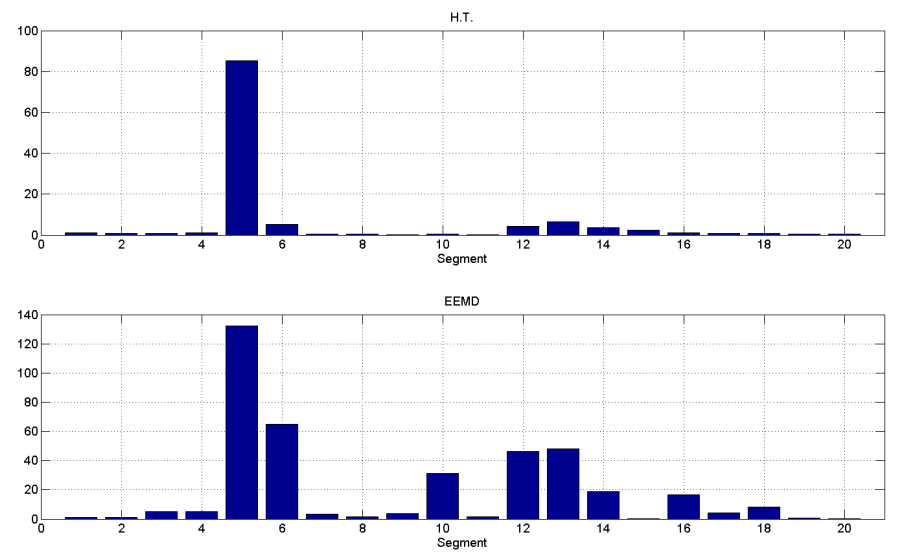

Fig. 11. HT and EEMD voltage sag detection criterion comparison.

\section{REFERENCES}

[1] M. A. Brown and S. Zhou, "Smart grid policies: an international review", WIREs Energy Environ 2013, 2: 121-139 doi:10.1002/wene.53

[2] M.G. Simões and al., "A comparison of smart grid technologies and progresses in Europe and the US," IEEE Trans. Industry Applications, vol. 48, n² 4, pp. 1154-1162, July/August 2012.

[3] M. Glinkowski, J. Hou and G. Rackliffe, "Advances in wind energy technologies in the context of smart grid," Proc. IEEE, vol. 99, nº, pp. 1083-1097, June 2011.

[4] E. Gómez-Lázaro, J.A. Fuentes, A. Molina-García, M. Cañas-Carretón, "Characterization and visualization of voltage dips in wind power installations," IEEE Trans. Power Delivery, vol. 24, n4, pp. 2071-2078, October 2009

[5] V. Ignatova, P. Grangon and S. Bacha, "Space vector method for voltage dips and swells analysis," IEEE Trans. Power Delivery, vol. 24, n4, pp. 2054-2061, October 2009.

[6] Y. Xia, S.C. Douglas and D.P. Mandic, "Adaptative frequency estimation in smart grid applications," IEEE Signal Processing Magazine, vol. 29, n5, pp. 44-54, September 2012.

[7] C. Fitzer, M. Barns and P. Green, "Voltage sag detection technique for a dynamic voltage restorer," IEEE Trans. Industry Applications, vol. 40, n 1 , pp. 203-212, January/February 2004.

[8] K.D. McBee and M.G. Simões, "Utilizing a smart grid monitoring system to improve voltage quality of customers," IEEE Trans. Smart Grid, vol. 3, n², pp. 738-743, June 2012.
[9] A.N. Milioudis, G.T. Andreou and D.P. Labridis, "Enhanced protection scheme for smart grids using power line communications techniquesPart I: Detection of high impedance fault occurrence," IEEE Trans. Smart Grid, vol. 3, n4, pp. 1621-1630, December 2012.

[10] A.N. Milioudis, G.T. Andreou and D.P. Labridis, "Enhanced protection scheme for smart grids using power line communications techniquesPart II: Location of high impedance fault position," IEEE Trans. Smart Grid, vol. 3, n4, pp. 1631-1640, December 2012.

[11] G.A. Orcajo, J.M. Cano, M.G. Melero, M.F. Cabanas, C.H. Rojas, J.F. Pedrayes and J.G. Noriella, "Diagnosis of electrical distribution network short circuits based on voltage Park's vector," IEEE Trans. Power Delivery, vol. 27, n4, pp. 1964-1972, October 2012.

[12] I. Kamwa, A. K. Pradhan, and G. Joos, "Robust Detection and analysis of power system oscillation using Teager-Kaiser energy Operator," IEEE Trans. Power Systems, vol. 26, n¹, pp.323-333, February 2011.

[13] T. Labos, J. Rezmer, P. Janik, H. Amarís, M. Alonso and C. Álvarez, "Application of wavelets and Prony method for disturbance detection in fixed speed wind farms," International Journal of Electrical Power and Energy Systems, vol. 31, n9, pp. 429-436, October 2009.

[14] C. Muscas, "Power quality monitoring in modern electric distribution systems," IEEE Instrumentation and Measurement Magazine, vol. 13, n`5, pp. 19-27, October 2010.

[15] O. Ozgonenel, T. Yalcin, I. Guney and U. Kurt, "A new classification for power quality events in distribution systems," Electric Power Systems Research, vol. 95, pp. 192-199, February 2013.

[16] Y. Amirat and M.E.H. Benbouzid, "A smart grid voltage sag detector using an EEMD-based approach," in Proceedings of the 2013 IEEE IEMDC, Chicago (USA), pp. 1-5, May 2013.

[17] http://www.expertmonitoring.com/doelibrary/index.html

[18] R.C. Leborgne, G. Olguin, J.M.C. Filho, M.H.J. Bollen "Differences in voltage dip exposure depending upon phase-to-phase and phase-toneutral monitoring connections," IEEE Trans. Power Delivery, vol. 22, n², pp. 1153-1159, April 2007.

[19] A. Oppenheim, R. Schafer and W. Padgett. Discrete-Time Signal Processing, Prentice Hall, 2009.

[20] Y. Amirat, V. Choqueuse, M.E.H. Benbouzid and S. Turri, "Hilbert transform-based bearing failure detection in DFIG-based wind turbines," International Review of Electrical Engineering, vol. 6, n³, pp. 12491256, June 2011.

[21] Y. Lei, J. Lin, Z. He and M.J. Zuo, "A review on empirical mode decomposition in fault diagnosis of rotating machinery," Mechanical Systems and Signal Processing, vol. 35, n ${ }^{\circ}-2$, pp. 108-126, February 2013.

[22] Y. Amirat, V. Choqueuse and M.E.H. Benbouzid, "Wind turbine bearing failure detection using generator stator current homopolar component ensemble empirical mode decomposition," in Proceedings of the 2012 IEEE IECON, Montreal (Canada), pp. 3937-3942, October 2012. 